\title{
The Effect of Cost of Living on Employee Wages in the Hospitality Industry
}

Cornell Hospitality Quarterly 2017, Vol. 58(2) 179-189 (C) The Author(s) 2016 Reprints and permissions: sagepub.com/journalsPermissions.nav DOI: $|0.1177 / 193896551664969|$ journals.sagepub.com/home/cqx (S) SAGE

\author{
Michael C. Sturman', Andrey D. Ukhov', and Sanghee Park²
}

\begin{abstract}
This study examines the effect of cost of living (COL) on employee wages in the hotel industry. Although prior research clearly indicates that $\mathrm{COL}$ and wages are positively related, there is a lack of research explicitly considering the specific nature of the relationship between $\mathrm{COL}$ and wages, and potential moderators to the relationship. Using a dataset containing information on 97 jobs over 67 cities, our study shows that while there is a positive effect of COL on wages, the adjustment is not equal in magnitude to the difference that the COL levels would indicate. Furthermore, the effect of $\mathrm{COL}$ decreases as the average wage for the given job increases. We also show differences in COL's effects for full-service versus limited-service hotels. We illustrate the implications of our findings by showing predicted wage rates for four jobs in five different cities, at both full-service and limit-service hotels. The study has implications for research, particularly for future work on $\mathrm{COL}$ and compensation. The findings also have important implications for practice, and may be particularly useful when managers need to set pay levels when local market data are unavailable.
\end{abstract}

\section{Keywords}

compensation; human resources; micro economics

The wages paid for a given job can vary substantially across locations. Wage differentials occur for a variety of reasons, including labor market conditions, unionization status (Lewis, 1986), local amenities and quality of life (DuMond, Hirsch, \& Macpherson, 1999; González-Chapela, 2007; Kim, Liu, \& Yezer, 2009; Roback, 1988; Winters, 2009), firm size (e.g., Bottazzi \& Grazzi, 2010; C. Brown \& Medoff, 1989; Lehmer \& Moller, 2010), and organizational compensation strategies (Weber \& Rynes, 1991). Wages are also expected to vary because of cost of living (COL) differences across locations (Black, Kolesnikova, \& Taylor, 2009; DuMond et al., 1999; Gerking \& Weirick, 1983; Kim et al., 2009; McHenry \& McInerney, 2014; Winters, 2009).

COL affects wages quite simply because if a given location has higher prices for goods and services providing a given level of utility, workers will require higher wages to work there (Winters, 2009). ${ }^{1}$ Yet, while it is essentially unquestioned that COL should influence pay levels, the nature of this relationship -is it linear, how strong is the effect - is largely unstudied. That is, for the purpose of pay system design, how much do companies adjust their wages based on local conditions? When sufficient local market data are available, this is not a critical issue, as pay can be set based on resultant market rates (Klein, Thompson, Cain, $\&$ Keegan, 2006). When these data are unavailable, though, it is far less clear what should be done. More academically, while it is not novel or particularly interesting to show a statistically significant positive relationship between COL and wages, the more interesting and to date unanswered question is, to what extent does COL affect wages, and what factors (if any) moderate this effect?

Knowing how to adjust pay systems for regional COL differences is important for both theory and practice. For theory, understanding COL's influence on pay levels is important for both economic research (Black et al., 2009) ${ }^{2}$ and management research (Gerhart \& Rynes, 2003; Gerhart, Rynes, \& Fulmer, 2009; Tracey \& Hinkin, 2008). To refine theory on the antecedents of pay levels, understanding how a contextual factor-which by definition exists in all possible locations - influences wage levels is crucial for understanding the causal influences of organizational costs. The precise nature of the relationship between $\mathrm{COL}$ and wages is also an open question. Given the importance for greater precision in organizational theory (Edwards \& Berry, 2010), investigating the functional form of COL's effects will help improve our understanding of organizational wage practices. A careful search of both economic and management

'Cornell University, Ithaca, NY, USA

${ }^{2}$ Rutgers University, Piscataway, NJ, USA

\section{Corresponding Author:}

Michael C. Sturman, The Kenneth and Marjorie Blanchard Professor of Human Resources, Professor of Management, School of Hotel Administration, Cornell University, 565E Statler Hall, Ithaca, NY 14853, USA.

Email: mcs5@cornell.edu 
journals revealed remarkably little research focused on COL. In short, while we do know that COL should affect wages, there is very little academic research investigating the specific nature of COL's effects.

Understanding the effects of COL is also an important practical issue for several reasons. First, as companies continue to grow from local to national organizations, their pay systems need to be able to accommodate COL differences across multiple locations (Klein et al., 2006). Without clear guidance, companies may end up over-adjusting or underadjusting pay levels and, as a result, may actually be paying a rate that is different from their desired compensation strategy. Second, even if a company is located in only one location, there may not be sufficient local pay survey data upon which to base a pay structure. Again, failure to have research-based advice means that resultant decisions may deviate from organizational goals. Third, even if local wage data are available for certain locations, the data reported in the survey may be flawed (Fay \& Tare, 2007). The more specific the location in the survey, the lower the sample size, thereby increasing the variability and potential error in reported values. Information reported in a pay survey may be based on sample sizes as low as five, making the accuracy of the point estimate of the market average subject to the sort of variability of very low power estimates. Fourth, COL is considered an important characteristic for pay setting purposes, and failure to adjust for $\mathrm{COL}$ is a major source of pay dissatisfaction (Dyer, Schwab, \& Theriault, 1976; Isaac, 2001). Companies need to adjust pay based on the level of the COL, and it would be helpful if research could provide guidance regarding the extent to which such adjustments should be made.

In the hospitality industry in particular, an understanding of the role of COL has significant implications. Labor costs account for nearly half of total expenses for many U.S. hotels (PKF Consulting, 2014), and thus pay practices are an important component of organizational strategic decisions. Research also shows that employees' perceptions of pay fairness predict both their effort and performance in hospitality jobs (Wu, Sturman, \& Wang, 2013) and can help prevent burnout (Pienaar \& Willemse, 2008). Other research has similarly shown that employee attitudes toward pay relate positively to job engagement and negatively to withdrawal (Jung \& Yoon, 2015). Understanding how to pay employees more effectively can also decrease organizational turnover (Guilding, Lamminmaki, \& McManus, 2014; Yang, Wan, \& Fu, 2012). Thus, if one goal of research is to facilitate evidence-based management (Rousseau, 2006; Rynes, Giluk, \& Brown, 2007), and as this is a highly salient issue in the hospitality sector, we need to investigate this sort of practical question for which we have no clear guidance.

In addition, while compensation strategy is important on its own, it is also closely related to other choices the firm makes. Decisions on compensation strategy can affect the firm as a whole and influence other decisions (Balkin \& Gomez-Mejia, 1987; Brenner, 2004). Faced with higher wages, for example, a firm may compensate with raising prices, increasing sales, changing operational techniques, or raising productivity. Labor economists have presented evidence consistent with productivity differences across locations with different wages (Fu \& Ross, 2013). ${ }^{3}$ Increased productivity resulting from wage increases has been recognized for decades, in the economics literature on "efficiency wages" and debates over the minimum wage (Lynn \& Boone, 2015), and in the management research on pay policies (M. Brown, Sturman, \& Simmering, 2003). With higher wages, workers may feel greater satisfaction with their job and may decide to put in greater work effort (Akerlof \& Yellen, 1990; Wu et al., 2013), and turnover may decline as the "cost of job loss" is greater (cf., Hausknecht \& Trevor, 2011). Yet, while the benefits of higher wages can often offset the costs (see Thompson \& Chapman, 2006, for a summary) ${ }^{4}$ there are diminishing returns to these benefits and the costs of greater wages will eventually outweigh their benefits (M. Brown et al., 2003). It is therefore important to have practical guidance for firm's compensation strategies with respect to COL not only because it is an important issue on its own but also because it is intertwined with other strategic decisions by the firm.

The purpose of this article is thus to examine the effect that COL differences across areas have on resultant pay levels. Specifically, we examine how local COL ratings affect the pay of employees in the hospitality industry. By doing so, our research contributes to the compensation field by proving greater insight into the elasticity of wages to $\mathrm{COL}$ differences. We also contribute to practice by providing prescriptive guidance for how to adjust pay levels when COL information is known but local wage data are unreliable or unavailable.

\section{COL and Wage Research}

\section{COL Background and Indices}

Basic economic theory would suggest that, in a frictionless world, wages would reach equilibrium, eventually making them equal across locations (DuMond et al., 1999). Yet research has studied interregional wage differentials as far back as the mid-1800s (cf., Gerking \& Weirick, 1983), seeking explanations to such observed differentials. The areas' COL is one factor that helps explain regional differences in nominal earnings (Gerking \& Weirick, 1983; Kim et al., 2009; Winters, 2009). Although certainly not the only factor influencing pay across locations, $\mathrm{COL}$ is a potentially critical factor in pay system design (Henderson, 2000).

COL indices are generally based on the idea of a "basket of goods" (Winters, 2009). This means an index estimates 
the cost of various types of goods, products, and services in different locations, and the index reflects their relative costs. These items can represent a broad range of categories. For example, prior to 2009, the Bureau of Labor Statistics computed its Consumer Price Index (CPI) based on costs of food and beverages, housing, apparel, transportation, medical care, recreation, education, communication, and other goods and services. After August of 2009, they revised the index to include expenditures in three broader categories: (1) food, (2) energy, and (3) all items less food and energy. Similarly, the American Chamber of Commerce Research Association (ACCRA) COL Index (Council for Community and Economic Research, 2009) considers the categories of grocery items, housing, utilities, transportation, health care, and miscellaneous goods and services. Altogether, these indices capture a sampling of costs that a consumer in a given area may face, and thus capture the relative costs associated with different locations.

\section{Effect of COL on Wages}

Although COL indices capture the cost of a sample of goods and services in various locations, it does not necessarily mean that businesses will (or should) adjust in a straightforward and linear manner. For one, not all goods and services are affected by local cost differences. For example, online purchases made through national retailers will generally not be affected (or have minimally different effects, such as from shipping costs or tax rates) by local cost conditions. Another example would be costs associated with a vacation stay outside of the area.

Different employees within a firm do not consume the same basket of goods. The consumption of employees with higher incomes may be expected to contain a larger proportion of non-local goods and services - such as luxury items, vacations, high-end durable goods (e.g., cars), and savings-which are less affected by COL levels. However, those earning lower wages will be more dependent on goods at the local level that reflect the COL differences, and will have fewer substitution options (e.g., a higher percentage of income is spent on food and housing) in terms of their discretionary spending. ${ }^{5}$ The proportion of income spent on such items as rent (local) and food should thus decline with the level of income. In this case, the effect of COL on wages should diminish at higher pay levels. Hence, wages will be more sensitive to the COL differences at lower wage levels. Thus, even if a company desires to keep someone's spending power constant across two locations, the extent to which they need to adjust salary levels should decrease as wages increase. We would therefore expect, for example, that adjustments for COL will be greater for a housekeeping position than for a rooms manager. It becomes important, then, to establish the nature of the relationship between wages and COL.
Individuals can also substitute various goods for other items within the basket of goods represented in the COL index. Winters (2009) provides such an example, stating,

Consumers can also shift away from consumption of relatively expensive housing toward consumption of local amenities, especially since local residents can often consume nature amenities at very low marginal cost (e.g., climate and coastal location) ... This appears quite likely along part of the California coast, where good weather permits substitution of outdoor living for indoor living. (p. 634)

Other research has indeed found empirical evidence supporting the view of substitutability between hosing and non-housing expenses (e.g., Piazessi, Schneider, \& Tuzel, 2007). Again, these findings are indicative of why wages may not fully adjust for COL differences.

In short, research has firmly established that $\mathrm{COL}$ and wages are positively related (Black et al., 2009), but the various effects associated with $\mathrm{COL}$ and its implications suggest that the relationship between COL and wage adjustments should not be uniform. Unfortunately, there is a notable lack of prescriptive guidance to facilitate organizational management. Online salary converters (e.g., http://cgi. money.cnn.com/tools/costofliving/costofliving.html; http:// www.bankrate.com/calculators/savings/moving-cost-ofliving-calculator.aspx $)^{6}$ that purportedly provide adjustments for pay based on contrasting COL levels, do clearly recommend changes in pay related to the COL differential of two locations; however, the adjustments they recommend are linear. For example, the CNN COL calculator ${ }^{7}$ indicates that a salary of US\$20,000 in Atlanta, Georgia, is comparable with a salary of US $\$ 23,825$ in Philadelphia, Pennsylvania. Similarly, US\$200,000 in Atlanta is comparable with US\$238,247 in Philadelphia. The bankrate.com calculator $^{8}$ produced similar results (US\$23,680 and US\$236,800, respectively). These systems make what are referred to as "full adjustments" for COL (cf., DuMond et al., 1999), and do necessarily represent the sort of adjustments companies actually make based on COL. Furthermore, such adjustments do not capture the expected different effects that we would predict should occur across varied pay levels.

Similarly, although compensation texts do describe how COL adjustments can be created and used by organizations to adjust pay systems for inflation (e.g., Bergmann \& Scarpello, 2002; Martocchio, 2011; Milkovich, Newman, \& Gerhart, 2014), they are silent regarding how to create pay structures where the same job may require different pay in different localities. These texts note that COL differentials play an important role in expatriate compensation package design, but there is no guidance for handling COL differences for typical pay systems. One notable exception, Henderson's (2000) compensation text, does acknowledge that "some nationwide firms that have employees 
performing similar jobs in different locations provide an area wage differential based on differences in living costs" (p. 629), but the text only refers the reader to the Locality Pay Areas, as defined by the Federal Government (U.S. Office of Personnel Management, 2016). ${ }^{9}$ These Locality Pay Areas provide some information on how the federal government adjusts pay by various regions, but it is only applicable to 32 locations in the United States (plus "Rest of U.S." and "Other Non-foreign Areas"). Alternatively, Henderson recommends that the decision maker can refer to local pay information based on regional pay surveys. Either way, the advice is still quite limited.

The lack of clear research advice does not signal, though, that COL differences are unimportant in practice. One practitioner article simply states that "geographic differentials are used quite frequently within the development of compensation plans" (Kovac, 2006, p. 83). In another practitioner article, Klein et al. (2006) identify three "myths" of locality pay differences: (a) that COL only affects jobs receiving pay at US $\$ 100,000$ or less, (b) that locality differences become smaller as wage levels increase, and (c) that locality differentials affect all industries and job families equally. Using data from the Mercer Human Resource Consulting's 2005 Benchmark Database, the authors claim to "bust" all three myths. Unfortunately, though, the article does not provide detail on any specific empirical results to substantiate the claims. Furthermore, the prescriptive recommendation is that "an employer needs data . . . to determine if a local wage rate is necessary for hiring talent from a particular location" (Klein et al., 2006, p. 50). In sum, even in the practitioner literature, prescriptive advice is quite limited, and completely silent regarding what to do when local data are unavailable.

As an applied field of study, research should inform practice (Rousseau, 2006); unfortunately, there are repeated instances of science-practitioner gaps (Rynes et al., 2007), and particularly notable gaps in the area of compensation (Deadrick \& Gibson, 2007; Gupta \& Shaw, 2014). We argue that a need exists for research to inform practice on how much to adjust wages based on COL data. Furthermore, as it is asserted that such adjustments are industry specific (Klein et al., 2006), and given how the hospitality industry is increasingly a multi-unit, multi-region business (Jones, 1999), this is a field that could benefit from such a directed effort. We therefore use a research-based approach to provide this prescriptive advice.

\section{The Study}

\section{Sample and Procedures}

We used data from two different sources to examine the relationship between COL and wages. For COL, we used the ACCRA COL Index data, the most widely used index
(DuMond et al., 1999; Kurre, 2003). We obtained 2010 COL data for a total of 318 different urban areas.

We collect hotel compensation data through the hospitality benchmark compensation survey from WageWatch (www.wagewatch.com). WageWatch (2016) conducts online pay surveys for a variety of industries, including the hospitality industry. Their 2010 Hospitality Benchmark Compensation Survey collects data from hotel companies throughout the United States, representing 91 different markets (which includes all 50 states) and 7,628 properties in the lodging, gaming, golf, and vacation ownership segments. Companies (typically human resource professionals) provide WageWatch with compensation data on up to 289 hourly, supervisory, and management positions. WageWatch is a commercial company, and thus clearly the companies providing data are not chosen through any sort of random selection. Nonetheless, the size of the survey and available data suggest that the pay survey is a highly comprehensive survey of pay information across the U.S. market. The advantage of focusing on one industry in this study is the level of detail in the data. It also means that there are no industry-level effect differences in our findings.

The database includes variables such as starting salaries and average salaries for a variety of job positions under each department in hotels. ${ }^{10}$ In particular, we selected 16 departments, which include the majority (and often all) of the positions typically within both full-service and limitedservice hotels. ${ }^{11}$ We also collected the national average compensation information for each job position. We sought wage information on 148 different jobs, across 114 cities.

Note that because general managers had notably different pay levels than all other jobs in the database, and as research indicates general managers to be notably different than other employees for a variety of reasons (Hodari \& Sturman, 2014; Nebel \& Ghei, 1993), we excluded general managers from our analyses so as to not skew or otherwise distort our results. Furthermore, because not all locations had all hotel jobs, and not all cities had the required 5+ data points required to report wage information, ${ }^{12}$ the usable dataset contained 97 jobs across 67 cities, although not all 97 jobs had data from all 67 cities. Ultimately, the final dataset had 2,411 job-city data points, because there were multiple observations per job.

\section{Analysis of Data}

To analyze the relation between wages and COL, we use several regression models. We start with simple models and include additional variables, building up to a model that captures the potentially variable impact of COL on wages. The dependent variable in our regression equations is the average hourly wage rate. Data from salaried positions were converted to equivalent hourly wages by dividing the stated salary by 2,080 (i.e., 52 weeks $\times 40 \mathrm{hr}$ per week). Although 


\section{Exhibit 1:}

Summary Statistics $(N=2,4 I I)$.

\begin{tabular}{|c|c|c|c|c|c|c|}
\hline & \multirow[b]{2}{*}{ M } & \multirow[b]{2}{*}{ SD } & \multicolumn{4}{|c|}{ Correlations } \\
\hline & & & $\mathrm{COL}$ & Hotel Type & Salaried & $\begin{array}{c}\text { National Pay } \\
\text { Average }\end{array}$ \\
\hline $\mathrm{COL}$ & 111.60 & 20.13 & 1.00 & & & \\
\hline Hotel type & 0.68 & 0.47 & .14 & 1.00 & & \\
\hline Salaried & 0.15 & 0.36 & -.05 & -.05 & 1.00 & \\
\hline National pay average & 12.97 & 6.12 & -.01 & .12 & .76 & 1.00 \\
\hline Hourly wage rate & 13.50 & 6.93 & .15 & .14 & .70 & .93 \\
\hline
\end{tabular}

Note. Correlations greater than .03 are significant at $p<.05$. For hotel type, full-service hotels are coded as I and limited-service hotels are coded as 0 . $\mathrm{COL}=$ cost of living.

it is common to use a logarithmic function to transform pay data, we first performed our analyses using the natural hourly value. We found that the regressions fit well and that the residuals were not highly skewed. Thus, we did not transform the data, which we feel facilitates the interpretation and use of our regressions.

Because we want to specifically investigate the effect that COL has on wage differentials, a key independent variable in our study is the national average wage for the given position. These data, also taken from the WageWatch pay survey, are based on the entire sample of available data (so, not just our urban areas). Any effects of COL should help explain deviations from the national average. Note that the COL index for our sample does not have a mean of 100 because the data come from a sample in a wage survey and not specifically of the entire U.S. market used to calculate the COL index. Note also that to rule out alternative explanations for our findings, we control for hotel type (coded as "1" for full-service hotels and " 0 " for limited-service hotels), as it is possible that the type of hotel may reward positions differently. Because we mathematically transformed salaried data to an hourly metric, we also created a dummy variable, labeled "Salaried," which equaled 1 if the data were originally from a salaried position and thus transformed into hourly wage data (otherwise, coded as zero). Finally, because our data have multiple observations per city, and multiple observations per job, the observations were not strictly independent. We therefore used a random effects model, with error terms for both "job" and "city." These approaches address potential bias in standard error estimates due to the lack of independence across observations (Raudenbush \& Bryk, 2002).

\section{Results}

Summary statistics for our study's variables are shown in Exhibit 1. Exhibit 2 shows the results of our regression analyses. Model 1 is a regression of the hourly wage rate on national average for the position, hotel type (an indicator variable), and an indicator variable for whether the position is salaried or hourly. Model 1 shows that, not surprisingly, the national average pay rate for a given position is a very good predictor of the specific wage in a given location. In addition, full-service hotels pay somewhat more than limited-service hotels. Combined, this model explains $87 \%$ of the variance in wage levels. ${ }^{13}$

Model 2 adds the COL Index to the explanatory variables. Adding the COL index variable explains $2 \%$ more variance, and indeed shows that the COL is positively related to the pay of a given position. Controlling for other variables, wages are indeed higher in areas with higher COL.

Models 3 and 4, though, show that the effect of COL is not simple and linear. Model 3 adds the interaction of the COL Index with national pay average to the explanatory variables from the prior model (Model 2). Model 3 shows that the effect of COL diminishes at higher pay levels. Thus, as predicted, wages are more sensitive to COL differences at lower wage levels. This finding is consistent with the notion that, at higher wage levels, a lower portion of employee's consumption expenses is affected by local cost levels.

Model 4 adds additional explanatory variables: (a) the interaction of hotel type (full-service vs. limited-service) and national pay average, (b) the interaction of hotel type and COL index, (c) the square of the COL index, and (d) the interaction of hotel type, the COL index, and national pay average. The results show that the nature of adjustments made is larger at full-service hotels than limited-service hotels. The results also show that the effects of the COL, the national average pay rate, and the interaction of those two are different across the hotel types. The squared COL term was not statistically significant.

Note that we explored other additional models, which considered further interactions. These regressions, though, were either not significantly better fitting, or did not increase the overall $R^{2}$ of the model more than .001. Thus, for brevity, we do not report or discuss them here. 


\section{Exhibit 2:}

Regression Results Predicting Wage Rate $(N=2,4 \mathrm{II})$.

\begin{tabular}{|c|c|c|c|c|}
\hline & Model I & Model 2 & Model 3 & Model 4 \\
\hline Intercept & $-0.66(0.24)^{* * *}$ & 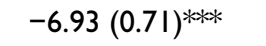 & $-8.63(0.87)^{* * *}$ & $2.64(4.39)$ \\
\hline Hotel type & $-0.0093(0.11)$ & $-0.044(0.11)$ & $-0.046(0.11)$ & $-8.91(1.57)^{* * *}$ \\
\hline National pay average & $1.08(0.012)^{* * *}$ & $1.08(0.012)^{* * *}$ & $1.22(0.044)^{* * *}$ & $0.72(0.12)^{* * *}$ \\
\hline Salaried & $-0.19(0.21)$ & $-0.20(0.21)$ & $-0.24(0.21)$ & $-0.095(0.21)$ \\
\hline COL index & & $0.058(0.0063)^{* * *}$ & $0.073(0.0077)^{* * *}$ & $-0.059(0.072)$ \\
\hline COL Index $\times$ National Pay Average & & & $-0.0012(0.00037)^{* *}$ & $0.0028(0.0010)^{* *}$ \\
\hline Hotel Type $\times$ National Pay Average & & & & $0.59(0.12)^{* * *}$ \\
\hline Hotel Type $\times$ COL Index & & & & $0.074(0.014)^{* * *}$ \\
\hline$(\mathrm{COL} \text { Index })^{2}$ & & & & $0.00031(0.00029)$ \\
\hline $\begin{array}{l}\text { Hotel Type } \times \text { COL Index } \times \text { National } \\
\text { Pay Average }\end{array}$ & & & & $-0.0048(0.001 \mathrm{I})^{\text {***** }}$ \\
\hline Pseudo $R^{2}$ & .870 & .896 & .897 & .899 \\
\hline
\end{tabular}

Note. All regressions are significant, and each subsequent model is significantly better fitting than the prior model at $p<.000 \mathrm{I}$. For hotel type, fullservice hotels are coded as I and limited-service hotels are coded as $0 . \mathrm{COL}=$ cost of living. $* p<.05 . * * p<.01 . * * * p<.0001$.

Although general managers were excluded from our prior analyses, we did examine them as their own group. Regressing wage rate on hotel type and COL, the effects of COL were non-significant; similarly, the effect of COL interacted with hotel type was also non-significant. ${ }^{14}$ Thus, for the position that is typically the highest paid position in any hotel, COL did not seem to be related to pay level across locations. This is consistent with our expectation that the effect of COL diminishes as pay level rises, and indeed indicates that adjustments for COL may ultimately decline to zero.

\section{Examples and Practical Implications}

Overall, the results support our more precise theoretical development about how COL affects pay levels. Effects are present and positive, but diminish at higher compensation levels. The nature of the business is also related to the magnitude of the adjustments. These results, though, while statistically significant and interesting, are somewhat difficult to interpret practically in this form. This is due to the number of variables in the analyses and the use of interactions. It is also not always clear whether statistical significance translates into practical significance. We thus now turn to demonstrating the potential utility of these findings for practical decision making.

To illustrate our results, we will look at four different positions - housekeeper, front desk agent, front desk manager, and director of marketing and sales - chosen to represent a range of positions in terms of complexity and because they are common positions, present at both limited and fullservice hotels. Using our regression results, we predict the pay level for these positions in five markets. We use the distribution of the COL data, and examine cities at the 10th, 25th, 50th, 75th, and 90th percentiles (which were DallasFort Worth, Atlanta, Denver, Philadelphia, and Washington D.C., respectively). Based on the results of Model 4 in Exhibit 2, Exhibit 3 shows the predicted wage levels for these jobs in both full-service and limited-service hotels.

The results clearly show that, although COL does influence the expected level of position pay, the differences are far smaller than online COL calculators (i.e., the fully adjusted estimates) would indicate. For example, consider comparing positions in Denver to Philadelphia. According to an online calculator, ${ }^{15}$ an employee in Philadelphia "should" make $17.6 \%$ more than what the employee makes in Denver; our results, however, indicate that the adjustment would be less. For example, a front desk agent is expected to receive an $11.0 \%$ differential rather than this $17.6 \%$ differential. For directors of marketing and sales, the adjustment is even less, with a differential of $5.3 \%$.

In short, COL does affect wages, and the sizes of the effects are not just statistically significant but do represent practically meaningful differences in pay levels. The magnitude of the effects, however, is far less than the simple, fully adjusted transformation that online sources typically indicate, and the difference depends on the type of hotel and the pay level of the position.

\section{Discussion}

Finding that $\mathrm{COL}$ is related to wages is not, in isolation, novel or insightful. The contribution of this study, however, comes from the specificity of understanding the nature of the relationship, and by empirically demonstrating how $\mathrm{COL}$ is moderated by other contextual factors. As a result, our study does more than provide a confirmation of a simple directional hypothesis, but adds precision to our understanding of 


\section{Exhibit 3: \\ Illustrating Our Findings.}

\begin{tabular}{|c|c|c|c|c|}
\hline & Housekeeper & Front Desk Agent & $\begin{array}{l}\text { Front Desk } \\
\text { Manager }\end{array}$ & $\begin{array}{l}\text { Director of } \\
\text { Marketing and Sales }\end{array}$ \\
\hline \multicolumn{5}{|l|}{ Full-service hotel } \\
\hline National average & US\$9.85 & US\$10.91 & US\$42, 120 & US\$88,000 \\
\hline $\begin{array}{l}\text { At I0th percentile of COL (Dallas-Fort } \\
\text { Worth, TX: COL }=91.8 \text { ) }\end{array}$ & US\$8.85 & US\$10.02 & US\$42,2। 4 & US\$93,213 \\
\hline $\begin{array}{l}\text { At 25th Percentile of COL (Atlanta, GA: } \\
\text { COL }=95.5 \text { ) }\end{array}$ & US\$9.03 & US\$10.20 & US\$42,48I & US\$93,240 \\
\hline $\begin{array}{l}\text { At 50th Percentile of COL (Denver, CO: } \\
\text { COL }=103.1 \text { ) }\end{array}$ & US\$9.43 & US\$10.59 & US $\$ 43,008$ & US\$93,356 \\
\hline $\begin{array}{l}\text { At 75th Percentile of COL (Philadelphia, PA: } \\
\text { COL }=126.4)\end{array}$ & US\$10.92 & US\$12.04 & US\$45,467 & US\$94,229 \\
\hline $\begin{array}{l}\text { At 90th Percentile of COL (Washington, } \\
\text { DC: } \mathrm{COL}=139.9)\end{array}$ & US\$1I.95 & US\$13.05 & US\$47,200 & US\$95,090 \\
\hline \multicolumn{5}{|l|}{ Limited-service hotel } \\
\hline National average & US\$9.00 & US\$9.75 & US $\$ 33,653$ & US $\$ 58,500$ \\
\hline $\begin{array}{l}\text { At I0th percentile of COL (Dallas-Fort } \\
\text { Worth, TX: COL }=91.8)\end{array}$ & US\$8.45 & US\$9.24 & US\$32,975 & US\$58,956 \\
\hline $\begin{array}{l}\text { At 25th percentile of COL (Atlanta, GA: } \\
\text { COL }=95.5)\end{array}$ & US\$8.58 & US\$9.36 & US\$33,158 & US $\$ 59,009$ \\
\hline $\begin{array}{l}\text { At 50th percentile of COL (Denver, CO: } \\
\mathrm{COL}=103.1 \text { ) }\end{array}$ & US\$8.87 & US\$9.64 & US\$33,595 & US\$59, 179 \\
\hline $\begin{array}{l}\text { At 75th percentile of COL (Philadelphia, PA: } \\
C O L=126.4)\end{array}$ & US\$9.99 & US\$10.74 & US\$35,449 & US\$60,219 \\
\hline $\begin{array}{l}\text { At 90th percentile of COL (Washington, } \\
\text { DC: } C O L=139.9)\end{array}$ & US\$10.82 & US\$II.55 & US $\$ 36,879$ & US\$6I,I77 \\
\hline
\end{tabular}

Note. COL $=$ cost of living.

COL's effects, thereby providing useful insights both for future research and for practice.

\section{Contributions to Research}

One key insight from this article is that COL measures may not represent the same COL experience for all people in the same region, as the effects of COL depend on the pay level being received. The "basket of goods" approaches used by COL measures provided the basis for our expectation that a given area's COL may not affect all people in the area equally. Although it seems that all individuals are affected by local COL to some degree (such as from housing and food costs), the proportion of income devoted to local goods and the need of individuals to limit themselves to local goods decrease as income increases. In other words, elasticity of consumption of different goods with respect to income is different for different income levels. The effects of COL are thus truly a person-dependent effect, even though organizations need to make COL adjustments on the basis of an individual job in a specific location.

Differences in the impact of COL on pay across job levels also suggest that studies using COL as a control variable may not be fully accounting for COL's effects. Simple linear adjustments for COL will not appropriately "equalize" pay across locations, nor does using COL as a city-level approximation of costs truly represent how different individuals are affected by COL. In short, our results indicate that any research using COL, as a key independent or control variable, needs to consider the complexity of its effects. The key here becomes the modeling of elasticity of consumption of different individuals. Therefore, the design of any empirical study that involves COL must account for potential differences in such elasticities.

Another key implication of our findings stems from our discovered differences of COL's effects for full-service hotels versus limited-service hotels. This finding, most simply, provides further evidence of the complexities associated with across-area differences. More importantly, these findings suggest that adjustments for COL depend on the type of business, perhaps indicating that adjustments for COL are related to product type, competitive environment, or organizational strategy. Our study cannot speak to which sort of organizational effects moderate the effect of COL on wages, but they do indicate that there are effects beyond just the level of analysis of the job. Organizational approaches to COL may be influenced by other organizational characteristics, including competitive strategy. The way in which 
multi-unit, multi-location organizations respond to local environments may be a valuable area for future strategic human resource research.

\section{Contributions to Practice}

With a better understanding of the precise nature of the relationship between COL and wages, this study provides actionable findings that can help in the process of pay setting. Although pay surveys are perhaps the most useful device for setting the specific wage rate for a given job, this information is often lacking. In all but the biggest cities, there is typically a lack of local data for at least some positions. In our dataset, we considered 97 different jobs across 67 cities. But of the 6,499 potential data points, we could only obtain job-city data points for 2,411 , or just below $38 \%$. Missing data is thus a very realistic and common problem, even in what is considered a very comprehensive pay survey. In fact, only three cities had data for all 97 positions, $50 \%$ of the cities had data on fewer than 38 positions, and $25 \%$ had 10 or fewer positions. In short, the vast majority of hotels are in locations where at least some information will be unavailable for pay setting purposes. It is highly likely that similar data issues are present in other pay surveys, which are often much less comprehensive than the one used in this study. Ours is the first study to provide a specific method for estimating this lacking information.

The regression results presented in Model 4 of Exhibit 2 provide a method for practitioners in the hotel industry to estimate local pay levels using the combination of independent variables reported in the analysis. That is,

$$
\begin{aligned}
& \text { Estimated Wage }=2.64+ \\
& (0.72 * \text { National Pay Average })- \\
& (8.91 * \text { Hotel Type })-(0.095 * \text { Salaried })- \\
& (0.059 * \text { COL Index })+ \\
& \left(\begin{array}{l}
0.0028 * \text { COL Index } * \\
\text { National Pay Average }
\end{array}\right)+ \\
& \left(\begin{array}{l}
0.59 * \text { Hotel Type } * \\
\text { National Pay Average }
\end{array}\right)+ \\
& (0.074 * \text { Hotel Type } * \text { COL Index })+ \\
& \left(0.00031 *(\text { COL Index })^{2}-\right. \\
& (0.0048 * \text { Hotel Type*COL Index * } \\
& \text { National Pay Average })
\end{aligned}
$$

Although this is a somewhat lengthy formula, it is a relatively straightforward way to estimate wage levels while only requiring information on the national pay average for a given job and the COL for the given location. Hotel type and salaried would both be known in any given decision context. In short, this study goes beyond just indicating that certain variables are related to wage rates, but provides a mechanism for practitioners to estimate that wage rate for a given position when local data are unavailable.

It is also worth noting that just because local pay data are available, it may be valuable to examine the degree to which it deviates from predicted values. As noted earlier, as pay surveys provide more specificity in terms of location, they sacrifice sample size. Thus, the most local estimates, which are perhaps most accurate in terms of reflecting local COL levels, are also the most subject to sampling error (with sample sizes as low as 5 serving as the basis for the calculation of the local wage). It may be valuable to balance predicted with observed data, weighting the resulting estimates based on the sample size of the pay survey data. Clearly, when pay survey data have many observations for a specific location, this is not necessary. But as many locations rely on samples with fewer than 10 observations, it may be worth balancing the predicted value derived above with the pay survey information to provide more stable estimates of local pay levels. It may even be valuable for pay survey companies to provide estimates of wages when data are unavailable, or provide algorithms that yield predicted wage levels that combine larger-sample based regression estimates with small-sample based observations.

\section{Limitations and Future Research}

Although this study has useful insights for both future research and practice, it also has aspects which limit the potential applicability of its findings. Most notably, our analyses are based on data from only the hotel industry. Given we show there are differences in pay practices just between full-service and limited-service hotels, it is likely that there are across-industry differences in pay practices as well. On the contrary, having data from only a single industry helps control for the sort of across-industry differences that we suggest may exist and therefore potentially confound any study that looked at COL using data from multiple industries. It also makes the results highly applicable to decision making specifically within the hotel industry. That said, it may be useful to have a sequence of research studies on individual industries, rather than one study across industries, to provide greater insight into how COL influences different sorts of jobs in different industries. In addition, future research could begin to explore the precise nature of organizational and industry characteristics which could influence the elasticity of wages to COL differences.

Our sample is also limited in that it is based on those who participated in a specific pay survey. Although this may be the largest pay survey of the hospitality industry, we cannot be sure how representative it is of the entire industry. As seen in our sample, the average COL was 111.50 , and not 100 . We thus know it is not perfectly representative of the geographic United States, although it may indeed be 
representative of the distribution of hotels across the country. Unfortunately, we simply cannot test or estimate the effects of the sample that chose to participate in the survey. Again, future research could consider other sources of data to help rule out selection issues as potential alternative explanations for our findings.

Another limitation, as well as opportunity for future research, is that our results are descriptive in that they reflect what hotels do; we do not examine how individuals perceive these actions. Although research has investigated pay issues with regard to recruitment (cf., Chapman, Uggerslev, Carroll, Piasentin, \& Jones, 2005), it is unclear how COL influences individual perceptions and whether individuals likewise perceive that their need for $\mathrm{COL}$ adjustments changes as incomes rise. Pay is a highly salient issue for employees, and COL issues are important in individuals' considerations of pay fairness. Although this study provides greater insights into the sort of COL adjustments made by organizations, research has yet to examine how the nature of COL adjustments affects employee attitudes and subsequent behaviors.

\section{Conclusion}

In this article, we examine the effects that COL differences across areas have on resulting pay levels. We assemble and analyze a new dataset and study how local COL differences affect the pay of different categories of employees in the hospitality industry. The hospitality industry is well suited for this investigation of the complexities in the relationship between COL and compensation. By focusing on one industry, the study avoids the need to account for potential crossindustry effects. At the same time, the nature of the hospitality industry is conducive to the investigation: It provides a sample of multi-unit, multi-location organizations with similar structure of jobs. Therefore, the industry brings into sharp focus the main sources of variation (variation across locations and variation across pay levels), while keeping the main organizational structure relatively constant.

We report several findings. We quantify the amount by which pay of full-service hotels exceeds pay of limited-service hotels. We also show that the effect of COL on wages is moderated. Although COL has a generally positive effect on wages, its effect diminishes at higher pay level. Wages are thus more sensitive to COL differences at lower wage levels. This finding is consistent with the economic notion of different consumption bundles at different income levels.

Our research contributes to the compensation field by providing greater insight into elasticity of wages to $\mathrm{COL}$ differences and by connecting to the economic reasoning behind the moderated relationship between wages and COL. We also contribute to practice by providing prescriptive guidance for how to adjust pay levels when COL information is known but local wage data are unavailable or unreliable.

\section{Declaration of Conflicting Interests}

The author(s) declared no potential conflicts of interest with respect to the research, authorship, or publication of this article.

\section{Funding}

The author(s) received no financial support for the research, authorship, or publication of this article.

\section{Notes}

1. For example, Glaeser and Maré (2001) show that in the United States, wages are 33\% higher in big cities than outside metropolitan areas.

2. For a related discussion, see also Bloom (1999) and Scarpello, Huber, and Vandenberg (1988).

3. In addition, several studies have shown that living wage laws (laws passed by municipalities to require living wages, rather than simply a minimum wage) have raised productivity and decreased turnover among affected firms - see Thompson and Chapman (2006), for a summary.

4. In addition to productivity increases, there are other adjustment channels that firms use in the face of higher wages. For example, in a fast food study in New Jersey and Pennsylvania, Card and Krueger $(1994,1995)$ report that pretax prices rose $4 \%$ faster as a result of the minimum wage increase in New Jersey-slightly more than the increase required to fully cover the cost increase caused by the minimum wage hike. Similar evidence is presented in Aaronson (2001), who finds that restaurant prices in the United States and Canada generally rise with changes in the wage bill, and that these changes are typically concentrated in the first quarter following a minimum wage increase.

5. Theoretical models are developed in González-Chapela (2007) and Black, Kolesnikova, and Taylor (2009).

6. http://cgi.money.cnn.com/tools/costofliving/costofliving. html, accessed on 1/7/2016. http://www.bankrate.com/calculators/savings/moving-cost-of-living-calculator.aspx, accessed on 1/7/2016.

7. .http://cgi.money.cnn.com/tools/costofliving/costofliving. html, accessed on 1/7/2016.

8. http://www.bankrate.com/calculators/savings/moving-costof-living-calculator.aspx, accessed on 1/7/2016.

9. See https://www.opm.gov/policy-data-oversight/pay-leave/ salaries-wages/2016/locality-pay-area-definitions/ Accessed $1 / 12 / 2016$.

10. Jobs are defined by WageWatch for them to collect information on jobs through their pay survey. Descriptions of jobs are provided by the organization, and respondents provide pay information for the jobs for which they have available data. Full descriptions of all jobs collected by WageWatch are provided by WageWatch (2016).

11. Full-service hotels are defined as "generally mid-price, upscale or luxury hotels with a restaurant, lounge facilities and meeting space, and offer minimum service levels, often including bell service and room service. These hotels report food and beverage revenue" (STR, 2016). Limited-service hotels are defined as "rooms-only operations, (i.e., without food and beverage service) or offer a bedroom and bathroom 
for the night, but very few other services and amenities. These hotels are often in the budget or economy group and do not report food and beverage revenue" (STR, 2016).

12. To avoid potential anti-trust violations, pay surveys must contain data from at least five survey participants (Kovac, 2005). Any job that had fewer than five companies providing data hence did not report pay information and therefore could not be used in the study.

13. Note that the variance component for "job" was non-significant; whereas the variance component for "city" was statistically significant $(p<.0001)$. This finding was consistent across all four models. Rerunning all four models without the random effect for "job" did not change the significance of any of the findings.

14. For general managers, there was only one position for city, thus making the random effects for job unnecessary. We ran models both with and without random effects for city, but in all cases, the effects of cost of living (COL) and the interaction of COL with hotel type were non-significant.

15. http://www.bankrate.com/calculators/savings/moving-costof-living-calculator.aspx

\section{References}

Aaronson, D. (2001). Price pass-through and the minimum wage. Review of Economics and Statistics, 83, 158-169.

Akerlof, G., \& Yellen, J. (1990). The fair wage-effort hypothesis and unemployment. The Quarterly Journal of Economics, $105,255-283$.

Balkin, D. B., \& Gomez-Mejia, L. R. (1987). Toward a contingency theory of compensation strategy. Strategic Management Journal, 8, 169-182.

Bergmann, T. J., \& Scarpello, V. G. (2002). Compensation decision making. Mason, $\mathrm{OH}$ : South-Western.

Black, D., Kolesnikova, N., \& Taylor, L. (2009). Earnings functions when wages and prices vary by location. Journal of Labor Economics, 27, 21-47.

Bloom, M. (1999). The performance effects of pay dispersion on individuals and organizations. Academy of Management Journal, 42, 25-40.

Bottazzi, G., \& Grazzi, M. (2010). Wage-size relation and the structure of work-force composition in Italian manufacturing firms. Cambridge Journal of Economics, 34, 649-669.

Brenner, M. (2004). The economic impact of living wage ordinances (Working Paper No. 80). Amherst: Political Economy Research Institute, University of Massachusetts Amherst.

Brown, C., \& Medoff, J. (1989). The employer size-wage effect. Journal of Political Economy, 97, 1027-1059.

Brown, M., Sturman, M. C., \& Simmering, M. (2003). Compensation policy and organizational performance: The efficiency, operational, and financial implications of pay levels and pay structure. Academy of Management Journal, 46, 752-762.

Card, D., \& Krueger, A. B. (1994). Minimum wages and employment: A case study of the fast-food industry in New Jersey and Pennsylvania. American Economic Review, 84, 772-793.

Card, D., \& Krueger, A. B. (1995). Myth and measurement: The new economics of the minimum wage. Princeton, NJ: Princeton University Press.
Chapman, D. S., Uggerslev, K. L., Carroll, S. A., Piasentin, K. A., \& Jones, D. A. (2005). Applicant attraction to organizations and job choice: A meta-analytic review of the correlates of recruiting outcomes. Journal of Applied Psychology, 90, 928-944.

Council for Community and Economic Research. (2009). ACCRA Cost of Living Index. Arlington, VA: Author.

Deadrick, D. L., \& Gibson, P. A. (2007). An examination of the research-practice gap in HR: Comparing topics of interest to HR academics and HR professionals. Human Resource Management Review, 17, 131-139.

DuMond, J. M., Hirsch, B. T., \& Macpherson, D. A. (1999). Wage differentials across labor markets and workers: Does cost of living matter? Economic Inquiry, 37, 577-598.

Dyer, L., Schwab, D. P., \& Theriault, R. D. (1976). Managerial perceptions regarding salary increase criteria. Personnel Psychology, 29, 233-242.

Edwards, J. R., \& Berry, J. W. (2010). The presence of something or the absence of nothing: Increasing theoretical precision in management research. Organizational Research Methods, 13, 668-689.

Fay, C. H., \& Tare, M. (2007). Market pricing concerns. WorldatWork Journal, 16(2), 61-69.

Fu, S., \& Ross, S. (2013). Wage premia in employment clusters: How important is worker heterogeneity? Journal of Labor Economics, 31, 271-304.

Gerhart, B., \& Rynes, S. L. (2003). Compensation: Theory, evidence, and strategic implications. Thousand Oaks, CA: SAGE.

Gerhart, B., Rynes, S. L., \& Fulmer, I. S. (2009). Pay and performance: Individuals, groups, and executives. Academy of Management Annals, 3, 251-315.

Gerking, S. D., \& Weirick, W. N. (1983). Compensating differences and interregional wage differences. Review of Economics and Statistics, 65, 483-487.

Glaeser, E. L., \& Maré, D. C. (2001). Cities and skills. Journal of Labor Economics, 19, 316-342.

González-Chapela, J. (2007). On the price of recreation goods as a determinant of male labor supply. Journal of Labor Economics, 25, 795-824.

Guilding, C., Lamminmaki, D., \& McManus, L. (2014). Staff turnover costs: In search of accountability. International Journal of Hospitality Management, 36, 231-243.

Gupta, N., \& Shaw, J. D. (2014). Employee compensation: The neglected area of HRM research. Human Resource Management Review, 24, 1-4.

Hausknecht, J. P., \& Trevor, C. O. (2011). Collective turnover at the group, unit, and organizational levels: Evidence, issues, and implications. Journal of Management, 37, 352-388.

Henderson, R. I. (2000). Compensation management in a knowledge-based world. Upper Saddle River, NJ: Prentice Hall.

Hodari, D., \& Sturman, M. C. (2014). Who's in charge now? The decision autonomy of hotel general managers. Cornell Hospitality Quarterly, 44, 433-447.

Isaac, J. E. (2001). Performance related pay: The importance of fairness. Journal of Industrial Relations, 43, 111-123.

Jones, P. (1999). Multi-unit management in the hospitality industry: A late twentieth century phenomenon. International Journal of Contemporary Hospitality Management, 11, 155-164. 
Jung, H. S., \& Yoon, H. H. (2015). Understanding pay satisfaction: The impacts of pay satisfaction on employees' job engagement and withdrawal in deluxe hotel. International Journal of Hospitality Management, 48, 22-26.

Kim, D., Liu, F., \& Yezer, A. (2009). Do inter-city differences in intra-city wage differentials have any interesting implications. Journal of Urban Economics, 66, 203-209.

Klein, A., Thompson, S., Cain, J., \& Keegan, J. (2006). Dispelling the myths of locality pay differentials. Workspan, 49(6), 49-51.

Kovac, J. C. (2005). Back to basics: Avoiding anti-trust litigation when conducting salary surveys. Workspan, 48(4), 71.

Kovac, J. C. (2006). Back to basics: Geographic differentials. Workspan, 49(2), 83.

Kurre, J. A. (2003). Is the cost of living less in rural areas? International Regional Science Review, 26, 86-116.

Lehmer, F., \& Moller, J. (2010). Interrelations between the urban wage premium and firm-size wage differentials: A microdata cohort analysis for Germany. Annals of Regional Science, 45, 31-53.

Lewis, H. G. (1986). Union relative wage effects: A survey. Chicago, IL: University of Chicago Press.

Lynn, M., \& Boone, C. (2015). Have minimum wage increases hurt the restaurant industry? The evidence says no! (Center for Hospitality Research Report).

Martocchio, J. J. (2011). Strategic compensation: A human resource management approach (6th ed.). Upper Saddle River, NJ: Prentice Hall.

McHenry, P., \& McInerney, M. (2014). The importance of cost of living and education in estimates of the conditional wage gap between black and white women. Journal of Human Resources, 49, 695-722.

Milkovich, G. T., Newman, J. M., \& Gerhart, B. (2014). Compensation (11th ed.). New York, NY: McGraw-Hill/ Irwin.

Nebel, E. C., \& Ghei, A. (1993). A conceptual framework of the hotel general manager's job. Journal of Hospitality \& Tourism Research, 16(3), 27-38.

Piazessi, M., Schneider, M., \& Tuzel, S. (2007). Housing, consumption, and asset pricing. Journal of Financial Economics, 83, 531-569.

Pienaar, J., \& Willemse, S. A. (2008). Burnout, engagement, coping and general health of service employee in the hospitality industry. Tourism Management, 29, 1053-1063.

PKF Consulting. (2014). Trends in the hotel industry: USA edition. Atlanta, GA: PKF Hospitality Research.

Raudenbush, S. W., \& Bryk, A. S. (2002). Hierarchical linear models (2nd ed.). Thousand Oaks, CA: SAGE.

Roback, J. (1988). Wages, rents, and amenities: Differences among workers and regions. Economic Inquiry, 26, 23-41.

Rousseau, D. M. (2006). Is there such a thing as "evidence based management." Academy of Management Review, 31, 256-269.

Rynes, S. L., Giluk, T. L., \& Brown, K. G. (2007). The very separate worlds of academic and practitioner periodicals in human resource management: Implications for evidencebased management. Academy of Management Journal, 50, 987-1008.
Scarpello, V., Huber, V., \& Vandenberg, R. (1988). Compensation satisfaction: Its measurement and dimensionality. Journal of Applied Psychology, 73, 163-171.

STR. (2016). A Guide to out Terminology. Retrieved from https:// www.strglobal.com/resources/glossary

Thompson, J., \& Chapman, J. (2006, February). The economic impact of local living wages (Working Paper). Washington, DC: Economic Policy Institute.

Tracey, J. B., \& Hinkin, T. R. (2008). Contextual factors and cost profiles associated with employee turnover. Cornell Hospitality Quarterly, 49(1), 12-27.

U.S. Office of Personnel Management. (2016). 2016 locality pay area definitions. Washington, DC: Author.

WageWatch. (2016). Retrieved from https://www.wagewatch. com/Account/Help/positions.aspx

Weber, C. L., \& Rynes, S. (1991). Effects of compensation strategy on job pay decisions. Academy of Management Journal, 34, 86-109.

Winters, J. V. (2009). Wages and prices: Are workers compensated for cost of living differences? Regional Science and Urban Economics, 39, 632-643.

Wu, X., Sturman, M. C., \& Wang, C. (2013). The motivational effects of pay fairness a longitudinal study in Chinese starlevel hotels. Cornell Hospitality Quarterly, 54, 185-198.

Yang, J. T., Wan, C. S., \& Fu, Y. J. (2012). Qualitative examination of employee turnover and retention strategies in international tourist hotels in Taiwan. International Journal of Hospitality Management, 31, 837-848.

\section{Author Biographies}

Michael C. Sturman ( $\mathrm{PhD}$, Cornell University) is the Kenneth and Marjorie Blanchard Professor of Human Resources at Cornell University's School of Hotel Administration. There, he teaches undergraduate, graduate, and executive education courses on human resource management and compensation. He also serves as the Associate Dean for Faculty Development, Director for the Center for Hospitality Research, and is an Associate Editor at the Journal of Applied Psychology.

Andrey D. Ukhov is an assistant professor of finance in the School of Hotel Administration. He is an expert on a wide range of investments, including preferred stocks, warrants, derivative securities, and convertibles. His research papers have been published in Management Science, the Journal of Financial and Quantitative Analysis, the Review of Finance, Quantitative Finance, the Economic History Review, the Journal of Real Estate Research, and other academic journals.

Sanghee Park is an assistant professor of Human Resources Management at Rutgers University School of Management and Labor Relations and has a doctorate in HR from the Hotel School at Cornell University. She is a Louis O. Kelso Fellow for the study of employee ownership, profit sharing, and broad-based equity compensation in the corporation and in the society of the United States and also a Morgan Stanley fellow in equity compensation. Her primary research interest is on the influence of compensation systems and her recent work appears in Journal of Applied Psychology and Human Resource Management. 